\title{
Epidermal growth factor protects the apical junctional complexes from hydrogen peroxide in bile duct epithelium
}

\author{
Srikar R Guntaka ${ }^{1}$, Geetha Samak ${ }^{1}$ Ankur Seth ${ }^{1}$, Nicholas F LaRusso ${ }^{2}$ and Radhakrishna Rao ${ }^{1}$
}

The tight junctions of bile duct epithelium form a barrier between the toxic bile and liver parenchyma. Disruption of tight junctions appears to have a crucial role in the pathogenesis of various liver diseases. In this study, we investigated the disruptive effect of hydrogen peroxide and the protective effect of epidermal growth factor (EGF) on the tight junctions and adherens junctions in the bile duct epithelium. Oxidative stress in NRC-1 and Mz-ChA-1 cell monolayers was induced by administration of hydrogen peroxide. Barrier function was evaluated by measuring electrical resistance and inulin permeability. Integrity of tight junctions, adherens junctions and the actin cytoskeleton was determined by imunofluorescence microscopy. Role of signaling molecules was determined by evaluating the effect of specific inhibitors. Hydrogen peroxide caused a rapid disruption of tight junctions and adherens junctions leading to barrier dysfunction without altering the cell viability. Hydrogen peroxide rapidly increased the levels of p-MLC (myosin light chain) and cSrc(pY418). ML-7 and PP2 (MLCK and Src kinase inhibitors) attenuated hydrogen peroxide-induced barrier dysfunction, tight junction disruption and reorganization of actin cytoskeleton. Pretreatment of cell monolayers with EGF ameliorated hydrogen peroxide-induced tight junction disruption and barrier dysfunction. The protective effect of EGF was abrogated by ET-18- $\mathrm{OCH}_{3}$ and the Ro-32-0432 (PLC $\gamma$ and PKC inhibitors). Hydrogen peroxide increased tyrosine phosphorylation of ZO-1, claudin-3, E-cadherin and $\beta$-catenin, and pretreatment of cells with EGF attenuated tyrosine phosphorylation of these proteins. These results demonstrate that hydrogen peroxide disrupts tight junctions, adherens junctions and the actin cytoskeleton by an MLCK and Src kinase-dependent mechanism in the bile duct epithelium. EGF prevents hydrogen peroxide-induced tight junction disruption by a PLC $\gamma$ and PKC-dependent mechanism.

Laboratory Investigation (2011) 91, 1396-1409; doi:10.1038/labinvest.2011.73; published online 23 May 2011

KEYWORDS: adherens junctions; cholangiocyte; EGF; oxidative stress; protein kinase; tight junction

The luminal surface of intra- and extra-hepatic bile ducts is lined by a monolayer of cholangiocytes (epithelial cells). This cholangiocyte monolayer forms a barrier to the diffusion of the various injurious agents from the bile duct lumen into the hepatic parenchyma. ${ }^{1}$ The tight junctions, a multi-protein complex, along the apical end of the cell provide the barrier function of different epithelia. Disruption of bile duct epithelial integrity is implicated in the pathogenesis of liver diseases that affect biliary tree, such as primary sclerosing cholangitis (PSC) and primary biliary cirrhosis (PBC). ${ }^{2-5}$ Disruption of tight junction integrity would allow regurgitation of bile acids or other noxious agents into the hepatic parenchyma from the bile duct lumen. ${ }^{6}$ As of now, most of the knowledge we have on the structure and regulation of tight junctions has been adapted from what is known about the tight junctions of intestinal and renal epithelia. Very little is known about the structure and regulation of tight junctions in the bile duct epithelium.

The tight junctions are composed of many proteins, including transmembrane proteins such as occludin, claudins and junctional adhesion molecules, and intracellular scaffold proteins such as zona occludens (ZO-1, ZO-2, ZO-3). The scaffold proteins and other associated tight junction proteins interact with the perijunctional actomyosin ring. The integrity of actomyosin ring and MLCK (myosin light chain kinase) activity have a crucial role in the regulation of tight junction integrity. Additionally, numerous signaling proteins such as c-Src, phosphatidylinositol 3-kinase, ERK, PKC

\footnotetext{
${ }^{1}$ Department of Physiology, University of Tennessee Health Science Center, Memphis, TN, USA and ${ }^{2}$ Department of Medicine, Mayo Clinic, Rochester, MN, USA Correspondence: Dr RK Rao, PhD, Department of Physiology, University of Tennessee, 894 Union Avenue, Nash 426, Memphis, TN 38163, USA. E-mail: rrao2@uthsc.edu

Received 2 November 2010; revised 22 November 2010; accepted 29 November 2010
} 
$\mathrm{PKC} \eta, \mathrm{PP} 1$ and PP2A directly interact with tight junction proteins, indicating their potential role in the regulation of tight junction integrity. ${ }^{7}$ The pharmacologic and molecular evidence support the fact that tight junctions and paracellular permeability are indeed regulated by signaling molecules such as intracellular calcium, cyclic AMP, GTPase switch protein, protein kinases and protein phosphatases in the intestinal and renal epithelia. ${ }^{7,8}$ However, the role of such signaling mechanisms in the regulation of bile duct epithelium is poorly understood. Adherens junctions are prominent junctional complexes in the intestinal and other epithelia. E-cadherin and catenins are the predominant proteins that are involved in the assembly of adherens junctions. But, there is no much information available regarding the adherens junctions in bile duct epithelium. One study, reported nearly two decades ago, described the presence of an adherens junction-like structure in the bile duct epithelium. ${ }^{9}$

A significant body of evidence indicates that oxidative stress has an important role in the pathogenesis of liver diseases. Compromised antioxidant defense mechanism and elevated oxidative stress was detected in the liver of patients with PSC and PBC. ${ }^{10-12}$ Serum oxidative stress level was shown to be elevated in patients with cholecystic bile duct injury. ${ }^{13}$ Hepatic oxidative stress was also detected in experimental cholecystic injury. ${ }^{14-16}$ Superoxide dismutase gene therapy attenuated the experimental cholestasis-induced liver fibrosis. ${ }^{17}$ The mechanism of oxidative stress-induced liver injury is poorly understood. Very little information is available regarding the oxidative stress effect on bile duct epithelial function. One study demonstrated that nitric oxide-mediated inhibition of DNA repair potentiates DNA damage in cholangiocytes. ${ }^{18}$ However, there is no information available regarding the effect of hydrogen peroxide or oxidative stress on the bile duct epithelial functions.

In the present study, we investigated the effect of hydrogen peroxide-induced oxidative stress on tight junction and adherens junction integrity and the mechanism associated with it in cholangiocyte monolayers. We further evaluated the epidermal growth factor (EGF)-mediated amelioration of tight junction disruption. EGF is a well-established gastrointestinal mucosal protective factor. However, its effect on bile duct function is unknown. NRC-1 cell monolayers were mainly used for this study. The effect of hydrogen peroxide and EGF on barrier function was confirmed in Mz-ChA-1 cell monolayers.

\section{MATERIALS AND METHODS} Chemicals

Cell culture supplies were obtained from Invitrogen (San Jose, CA, USA), and Transwell inserts and other cell culture plastic wares were purchased from Costar (Cambridge, MA, USA). Rat-tail collagen (Type I), ML-7, PP2, genistein and FITC-inulin were obtained from Sigma chemical company (St Louis, MO, USA). Ro-32-0432 and ET-18- $\mathrm{OCH}_{3}$ were purchased from EMD Biochemicals (Gibbstown, NJ, USA).
Other fine chemicals and laboratory supplies were purchased from Fisher Scientific (Tustin, CA, USA) or Sigma chemical company.

\section{Antibodies}

Mouse monoclonal anti-occludin antibody and rabbit polyclonal anti-occludin, anti-ZO-1, anti-claudin-3 and anti- $\beta$ catenin antibodies were purchased from Zymed laboratories (South San Francisco, CA, USA). Biotin-conjugated antiphospho-tyrosine (p-Tyr), anti-E-cadherin and anti-actin antibodies were purchased from BD Transduction laboratories (Lexington, KY, USA). Mouse monoclonal anti-Src, anti-p-MLC and anti-c-Src(pY418) antibodies were purchased from Upstate Biotechnology (Lake Placid, NY, USA). AlexaFlour-488-conjugated anti-mouse IgG was obtained from Molecular Probes (Eugene, OR, USA). Cy3-conjugated anti-rabbit IgG was purchased from Sigma Immunochemicals (St Louis, MO, USA).

\section{Cell Culture}

NRC-1 cells (normal rat cholangiocytes) were cultured in DMEM-F12 supplemented with $10 \%$ fetal bovine serum, vitamin mix, chemically defined lipid mix, insulin-transferrin-selenium mix, nonessential amino acids and antibiotics (penicillin and streptomycin) as described before. ${ }^{5}$ These cells were originally derived from intra-hepatic cholangiocytes. Cells were cultured on plates or Transwell inserts (12 or $24 \mathrm{~mm}$ diameter) coated with rat-tail type I collagen. All experiments were performed on 5-6 days post-seeding in confluent monolayers. Mz-ChA-1 cells were grown in CMRL Medium-1066 containing 10\% fetal bovine serum, L-glutamine and antibiotics (penicillin and streptomycin). Cells were passaged at $90 \%$ confluence and seeded onto Transwell inserts $(12 \mathrm{~mm})$. Experiments were conducted on $4-5$ days post-seeding.

\section{Hydrogen Peroxide Treatment}

Cell monolayers were preincubated in DMEM for $1 \mathrm{~h}$ with varying concentrations of hydrogen peroxide $(100-500 \mu \mathrm{M})$ at both the apical and basal chambers and placed in $37^{\circ} \mathrm{C}$ incubator. At varying times after hydrogen peroxide, the paracellular permeability was evaluated by measuring transepithelial electrical resistance (TER) and unidirectional flux of FITC-inulin. Inhibitors such as PP2 $(3 \mu \mathrm{M})$ and ML-7 $(10 \mu \mathrm{M})$ were administered $60 \mathrm{~min}$ before hydrogen peroxide administration. EGF $(30 \mathrm{nM})$ was added $10 \mathrm{~min}$ before hydrogen peroxide. ET-18- $\mathrm{OCH}_{3}(15 \mu \mathrm{M})$ or Ro-32-0432 $(1 \mu \mathrm{M})$ was administered 50 min before EGF administration. Control monolayers received the inhibitor in the absence of EGF and hydrogen peroxide.

\section{Cell Viability Assay}

Cell viability was assessed by measuring lactate dehydrogenase (LDH) activity in the incubation medium $3 \mathrm{~h}$ after incubation with or without $500 \mu \mathrm{M}$ hydrogen peroxide. $\mathrm{LDH}$ 
activity measured using a kit form Sigma chemical company. The metabolic activity of cells was evaluated by using WST-1 cell viability assay kit from Clontech (Mountain View, CA, USA) according to the vendor's instructions. This assay involves cleavage of stale tetrazolium salt of WST-1 to a soluble formazan, which is measured by colorimetric method. The conversion of WST-1 occurs at cell surface by metabolically active cells, largely dependent on glycolytic production of $\mathrm{NADH}$. Therefore, color produced is directly proportional to the number of metabolically active cells. A loss of cell viability results in reduced rate of WST-1 conversion and low color development.

\section{Measurement of TER}

TER was measured as described earlier ${ }^{5}$ using a Millicell-ERS electrical resistance system (Millipore, Bedford, MA, USA). The TER recorded in empty Transwell inserts (usually 50-80 Ohms $\bullet \mathrm{cm}^{2}$ ) was subtracted from all values.

\section{Unidirectional Flux of Inulin}

Inulin permeability was measured by incubating cell monolayers in the presence of $0.5 \mu \mathrm{g} / \mathrm{ml}$ FITC-inulin in the apical chamber. At varying times, $100 \mu \mathrm{l}$ aliquot of basal medium was withdrawn and fluorescence was measured in a microplate fluorescence reader (FLx-800, Bio-TEK Instruments, Winooski, VT, USA). Flux of FITC-inulin into the basal well, was calculated as the percentage of total fluorescence administered into the apical well per hour per $\mathrm{cm}^{2}$ surface area.

\section{Immunofluorescence Microscopy}

Under various experimental conditions, cell monolayers were fixed in ice-cold acetone:methanol $(1: 1, \mathrm{v} / \mathrm{v})$ for $5 \mathrm{~min}$. The fixed cells were rehydrated in PBS (Dulbecco's saline containing $1.2 \mathrm{mM} \mathrm{CaCl}_{2}$ and $1 \mathrm{mM} \mathrm{MgCl} 2$ ) and permeabilized with $0.2 \%$ Triton-X100 in PBS. Cell monolayers were blocked with $4 \%$ nonfat milk in TBST $(20 \mathrm{mM}$ Tris, $\mathrm{pH} 8.0$, containing $150 \mathrm{mM} \mathrm{NaCl}$ and $0.5 \%$ Tween 20). Cells were then stained with a mixture of mouse monoclonal anti-occludin and rabbit polyclonal anti-ZO-1 antibodies or mouse monoclonal anti-E-cadherin and rabbit polyclonal anti- $\beta$ catenin antibodies. A mixture of AlexaFlour-488-conjugated anti-mouse IgG and Cy3-conjugated anti-rabbit IgG antibodies was used as secondary antibodies. Actin cytoskeleton was stained by incubation of paraformaldehyde-fixed cells with AlexaFluor-488-conjugated phalloidin. Cells were mounted and images were collected using a Zeiss LSM 5 PASCAL laser scanning confocal microscope and the LSM 5 PASCAL software (Release 3.2) as a series of images from $1.0 \mu \mathrm{m} \mathrm{XY} \mathrm{sections.} \mathrm{Images} \mathrm{were} \mathrm{stacked} \mathrm{by} \mathrm{using} \mathrm{the} \mathrm{Image} \mathrm{J}$ software and processed by Adobe Photoshop (Adobe Systems, San Jose, CA, USA).

\section{Analysis of Tyrosine Phosphorylated Proteins}

Proteins were extracted under denatured conditions using lysis buffer D (50 mM Tris buffer, $\mathrm{pH} 8.0$, containing $0.3 \%$
SDS, $2 \mathrm{mM}$ vanadate, $10 \mathrm{mM}$ sodium fluoride and protease inhibitors as described earlier) and heated at $100^{\circ} \mathrm{C}$ for $10 \mathrm{~min}$. Biotin-conjugated anti-p-Tyr was used to immunoprecipitate p-Tyr. Immunocomplexes were precipitated with streptavidin-agarose and immunoblotted for different proteins as described below.

\section{Immunoblot Analysis}

Proteins were separated by SDS-PAGE and transferred to PVDF membranes. Blots were probed for occludin, ZO-1, c-Src, p-MLC, c-Src(pY418), E-cadherin, $\beta$-catenin and claudin-3. HRP-conjugated anti-mouse IgG or anti-rabbit IgG antibodies were used as secondary antibodies. The blots were developed using the enhanced chemiluminescence method (Amersham, Arlington Heights, IL, USA).

\section{Statistics}

Comparison between two groups was made by the Student's $t$-tests for grouped data. The significance in all tests was derived at $95 \%$ or greater confidence level.

\section{RESULTS \\ Hydrogen Peroxide Induces Barrier Dysfunction in Cholangiocyte Monolayers}

To determine the influence of oxidative stress on the barrier function of bile duct epithelium, NRC-1 cell monolayers were exposed to hydrogen peroxide and the barrier function was evaluated by measuring TER and inulin permeability. Hydrogen peroxide reduced TER and increased inulin permeability in a time (Figure 1a and b) and dose (Figure 1c and d)-dependent manner, indicating that hydrogen peroxide increases the paracellular permeability. To determine the effect of hydrogen peroxide on cell viability, we evaluated its effect on LDH release and cell metabolic capacity as assessed by WST-1 assay. Under our experimental conditions, hydrogen peroxide did not increase LDH release (Figure 1e) or decrease WST-1 activity (Figure 1f).

\section{Hydrogen Peroxide Disrupts Tight Junctions and Adherens Junctions}

Above data suggest that hydrogen peroxide increases paracellular permeability in NRC-1 cell monolayers without causing any loss of cell viability. Paracellular permeability in epithelial monolayers is restricted due to the presence of intact tight junctions. Although adherens junctions do not provide a physical barrier, they are known to indirectly regulate the integrity of tight junctions. Therefore, we examined the effect of hydrogen peroxide on the integrity of tight junctions and adherens junctions by immunofluorescence analysis of subcellular localization of occludin, ZO-1, E-cadherin and $\beta$-catenin. Occludin and ZO- 1 were colocalized at the intercellular junctions in the control cell monolayers, indicating the presence of intact tight junctions. Hydrogen peroxide treatment induced a redistribution of occludin and $\mathrm{ZO}-1$ from the intercellular junctions into the 

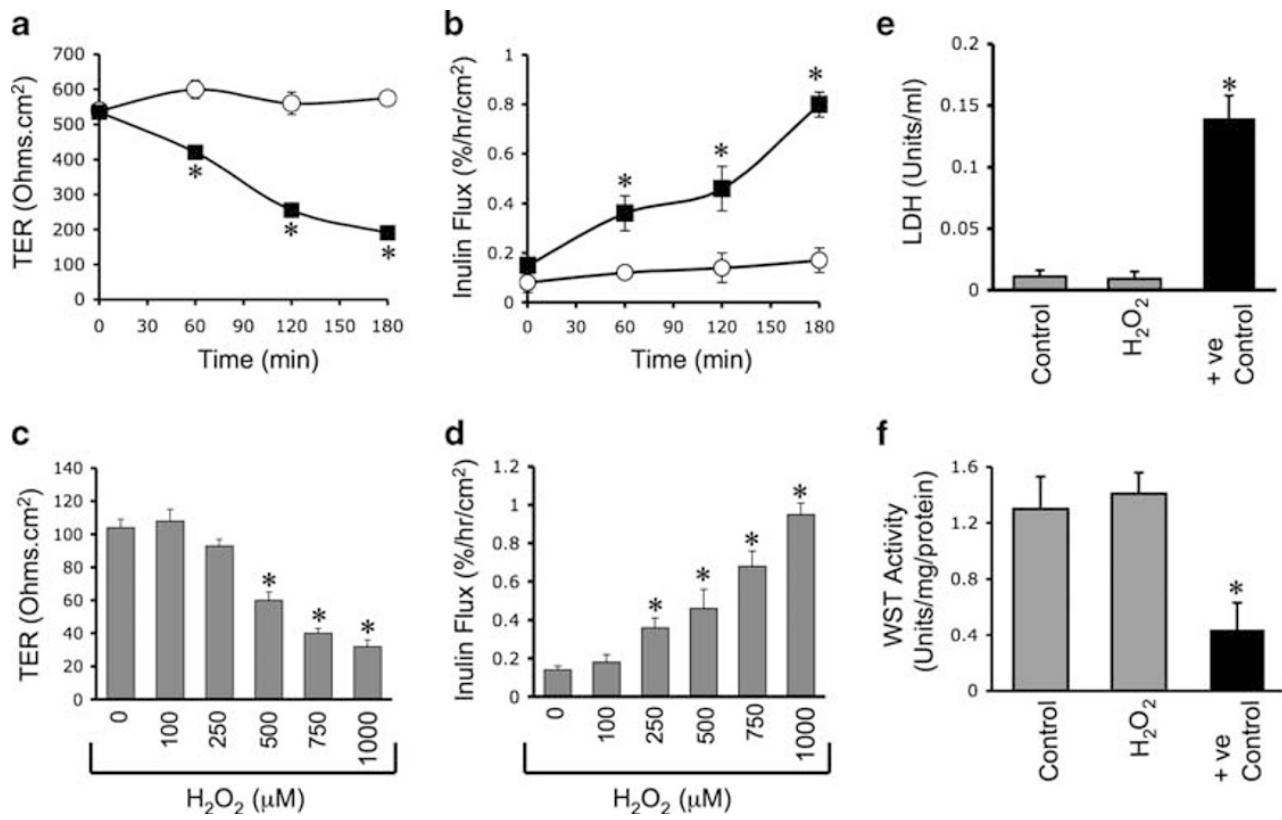

f

Figure 1 Hydrogen peroxide disrupts barrier function in NRC-1 cell monolayers. NRC-1 cell monolayers were incubated with $(\boldsymbol{\square})$ or without $(O)$ varying concentrations of hydrogen peroxide (c, $\mathbf{d})$ for varying times $(\mathbf{a}, \mathbf{b})$. TER $(\mathbf{a}, \mathbf{c})$ and inulin permeability $(\mathbf{b}, \mathbf{d})$ were measured. The incubation medium was assayed for LDH activity (e), and the cells were subjected to WST-1 viability test (f). Values are shown as mean \pm s.e.m. $(n=6)$. Asterisks indicate the values that are significantly $(P<0.05)$ different from the corresponding control values.

intracellular compartments in a time-dependent manner (Figure 2). E-cadherin and $\beta$-catenin were co-localized at the intercellular junctions in control cell monolayers, and hydrogen peroxide induced a redistribution of both E-cadherin and $\beta$-catenin from the intercellular junctions in a timedependent manner (Figure 3).

\section{MLCK Activity Mediates Hydrogen Peroxide-Induced Tight Junction Disruption and Barrier Dysfunction}

MLCK is well known to have a role in tight junction regulation in the intestinal ${ }^{19}$ and lung ${ }^{20}$ epithelial monolayers. Studies were therefore designed to determine the effect of hydrogen peroxide on MLCK activation and the effect of ML-7, an MLCK-selective inhibitor, on tight junction disruption. Pretreatment of cell monolayers with ML-7 significantly attenuated hydrogen peroxide-induced decrease in TER (Figure $4 \mathrm{~b}$ ) and increase in inulin permeability (Figure 4c). ML-7 also attenuated hydrogen peroxide-induced redistribution of occludin and ZO-1 from the intercellular junctions into the intracellular compartments (Figure 4d). ML-7 by itself did not influence TER, inulin flux or junctional distribution of occludin and ZO-1.

\section{Hydrogen Peroxide-Induced Disruption of Tight Junctions is Mediated by Src Kinase Activity}

Our previous studies demonstrated that tyrosine kinases, especially c-Src, have an important role in tight junction regulation in the intestinal epithelium. We, therefore, evaluated the role of tyrosine kinase activity in hydrogen peroxide-induced tight junction disruption in NRC-1 cell monolayers. Hydrogen peroxide rapidly increased the level of
c-Src(pY418) (Figure 5a), indicating an activation of c-Src in NRC-1 cell monolayers. Pretreatment of cell monolayers with genistein (a broad range tyrosine kinase inhibitor) or PP2 (a Src kinase inhibitor) significantly attenuated hydrogen peroxide-induced decrease in TER (Figure 5b) and increase in inulin permeability (Figure 5c). PP2 also attenuated hydrogen peroxide-induced redistribution of occludin and ZO-1 from the intercellular junctions (Figure 5d). Genistein or PP2 under the concentrations used, did not influence TER, inulin permeability or junctional distribution of occludin and ZO-1.

\section{Hydrogen Peroxide-Induced Activation of MLCK and c-Src are Independent of Each Other}

To investigate the interdependency of MLCK activation and c-Src activation, we determined the effect of ML-7 and PP2 on MLCK and c-Src activation. Pretreatment of cell monolayers with ML-7 attenuated hydrogen peroxide-induced increase in p-MLC levels (Figure 6), but p-MLC levels were unaffected by PP2. Similarly, hydrogen peroxide-induced increase in the levels of $\mathrm{c}-\mathrm{Src}(\mathrm{pY} 418)$ was attenuated by PP2, but not by ML-7 (Figure 6). These results indicate independent activation of MLCK and c-Src by hydrogen peroxide.

\section{Hydrogen Peroxide Induces Reorganization of Actin Cytoskeleton by an MLCK and Src Kinase-Dependent Mechanism}

The tight junction protein complex is known to intimately associate with the actomyosin ring, and disruption of actin cytoskeleton leads to disruption of tight junctions. ${ }^{21-23}$ In the control cell monolayers, actin is organized distinctly at the 

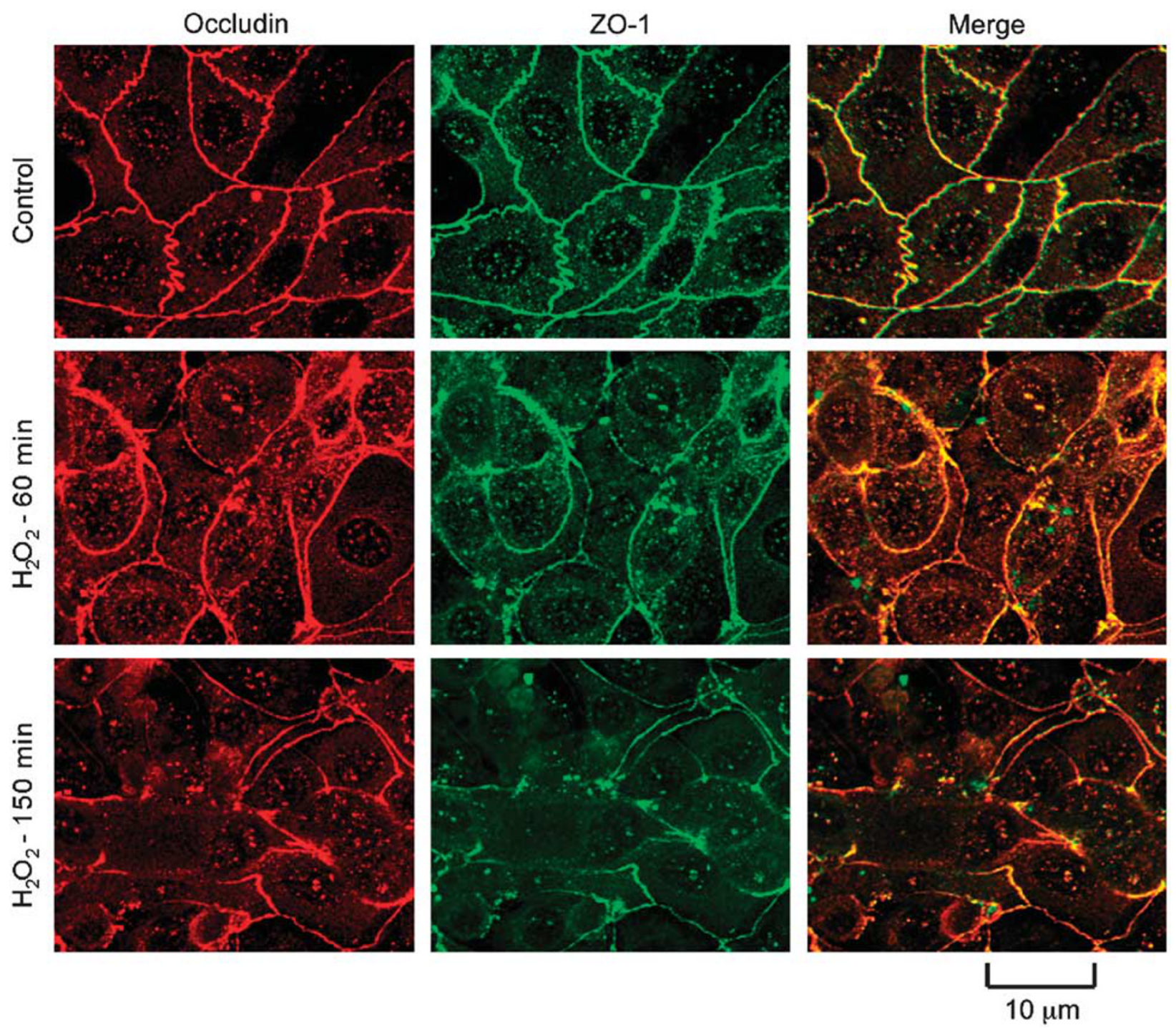

Figure 2 Hydrogen peroxide disrupts tight junctions. NRC-1 cell monolayers were incubated with or without hydrogen peroxide (500 $\mu \mathrm{M})$ for varying times. Cell monolayers were fixed and stained for occludin and ZO-1 by immunofluorescence method. Fluorescence images were collected using a confocal microscope.

apical, middle and basal parts (Figure 7). At the apical part, actin stains appear as uniformly distributed punctuates. In the middle part of the cell, the F-actin filaments appear to be organized as a ring at the perijunctional region. Network of weak stress fibers were seen at the basal part of the cell. Treatment with hydrogen peroxide resulted in a dramatic disorganization of F-actin arrangements at all three levels of the cell (Figure 7). Pretreatment of cell monolayers with ML-7 or PP2 preserved the normal organization of the actin cytoskeleton in hydrogen peroxidetreated cells.

\section{EGF Ameliorates Hydrogen Peroxide-Induced Tight Junction Disruption in NRC-1 Cell Monolayers}

EGF, a gastrointestinal mucosal protective factor, has been extensively investigated for its mucosal protective role in the gastrointestinal mucosa. ${ }^{24}$ But, there is no information available on the potential protective role of EGF in the bile ducts. We investigated the effect of EGF on hydrogen peroxide-induced tight junction disruption in NRC-1 cell monolayers. Pretreatment of cell monolayers with EGF for 10 min before hydrogen peroxide administration significantly attenuated hydrogen peroxide-induced decrease in TER (Figure 8a) and increase in inulin permeability (Figure 8b). EGF also attenuated hydrogen peroxide-induced redistribution of occludin and ZO-1 from the intercellular junctions (Figure 8c). EGF by itself did not cause significant change in TER, inulin flux or junctional distribution of occludin and ZO-1. The effect of EGF on hydrogen peroxide-induced tight junctions was significantly attenuated by pretreatment of cell monolayers with $0.3 \mu \mathrm{M}$ AG1478, a selective inhibitor of EGF receptor tyrosine kinase (data not shown). 

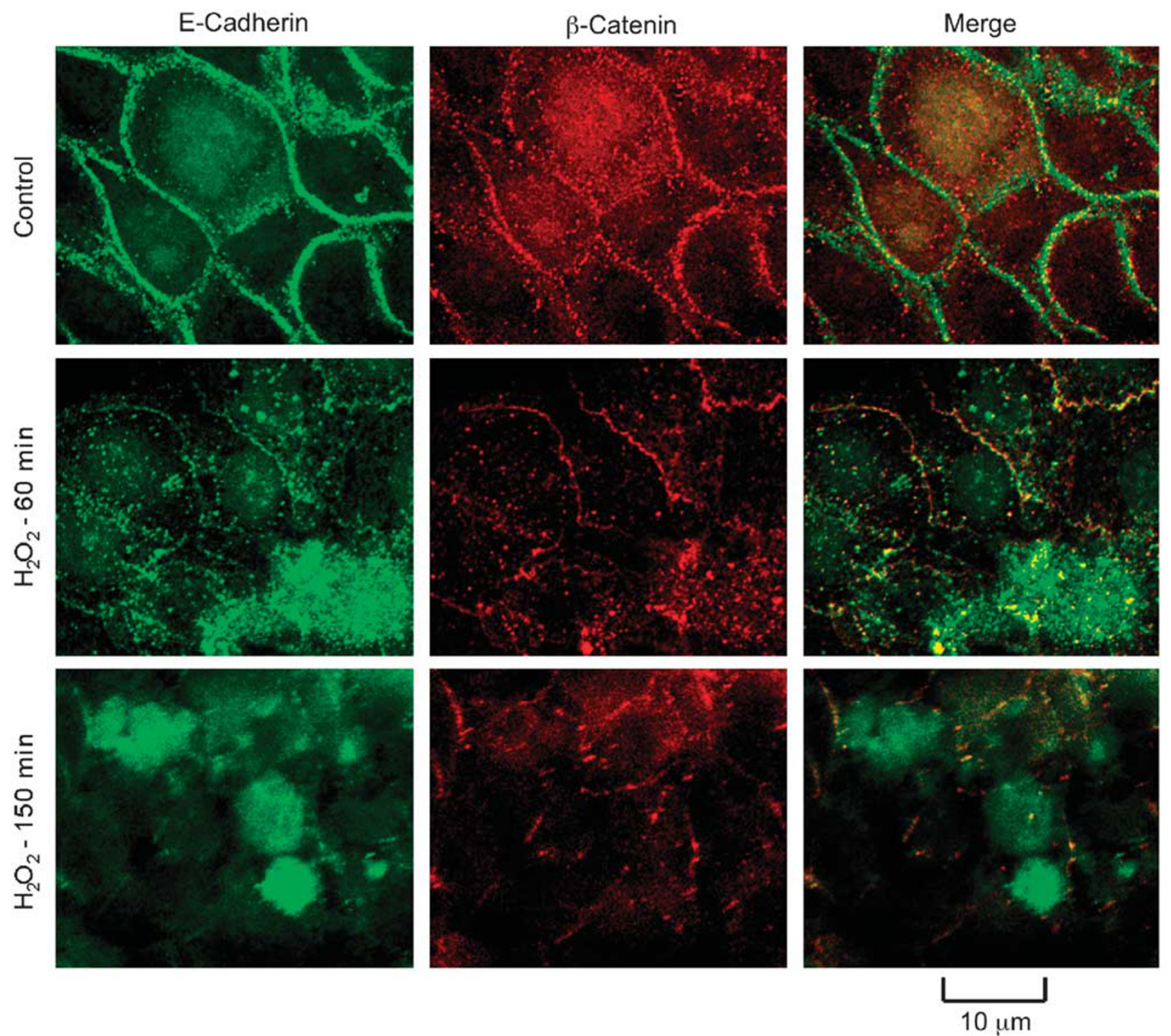

Figure 3 Hydrogen peroxide disrupts adherens junctions. NRC-1 cell monolayers were incubated with or without hydrogen peroxide (500 $\mu \mathrm{M}$ ) for varying times. Cell monolayers were fixed and stained for E-cadherin and $\beta$-catenin by immunofluorescence method. Fluorescence images were collected using a confocal microscope.

\section{EGF Attenuates Hydrogen Peroxide-Induced c-Src Activation and Tyrosine Phosphorylation of Tight Junction and Adherens Junction Proteins}

Previous studies showed that the integrity of tight junctions and adherens junctions is regulated by Src-mediated tyrosine phosphorylation of tight junction and adherens junction proteins. ${ }^{25,26}$ The present study shows that EGF pretreatment attenuates hydrogen peroxide-induced increase in the level of $c-S r c(p Y 418)$ in NRC-1 cell monolayers (Figure 9a). Hydrogen peroxide treatment increased the levels of tyrosine phosphorylated ZO-1, E-cadherin, $\beta$-catenin and claudin-3 (Figure 9b). EGF pretreatment reduced Tyr-phosphorylation of these proteins in hydrogen peroxide-treated cells. Tyrphosphorylated occludin levels were high in both untreated and hydrogen peroxide-treated cell monolayers (Figure 9b). EGF treatment reduced the levels of tyrosine phosphorylated occludin in both untreated and hydrogen peroxide-treated cell monolayers.

\section{PLC $\gamma$ and PKC Activities are Involved in EGF-Mediated Protection of Tight Junctions}

One of the major intracellular signaling pathways activated by EGF is PLC $\gamma$-mediated PKC activation as shown in Caco-2 cell monolayers. ${ }^{27}$ In the present study, we investigated the role of PLC $\gamma$ and PKC in EGF-mediated tight junction protection in NRC-1 cell monolayers. Pretreatment of cell monolayers with ET-18- $\mathrm{OCH}_{3}$, a PLC $\gamma$-selective 
a

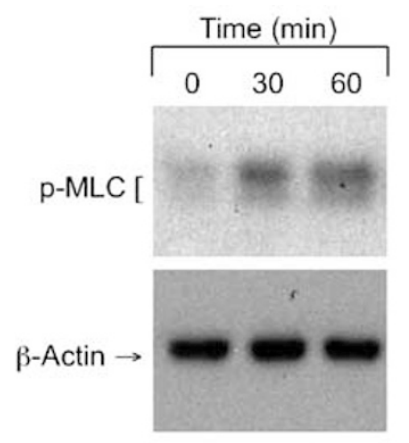

c

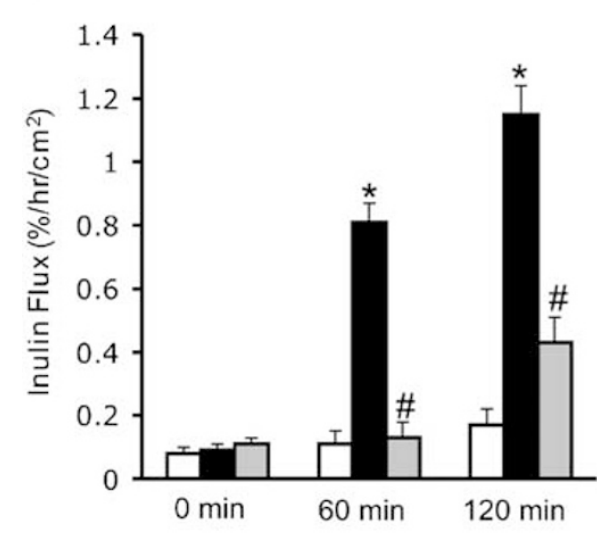

b

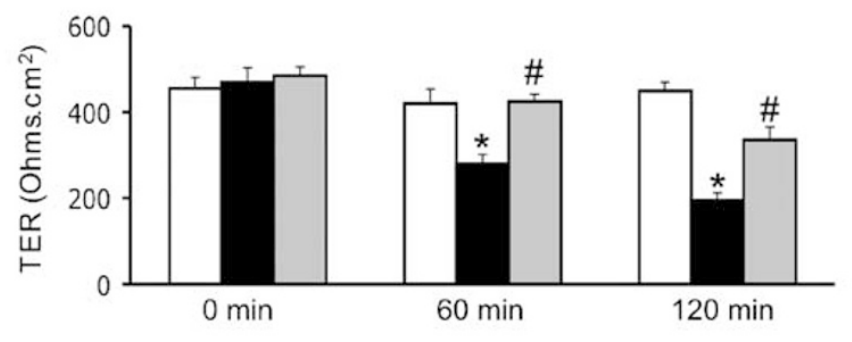

d
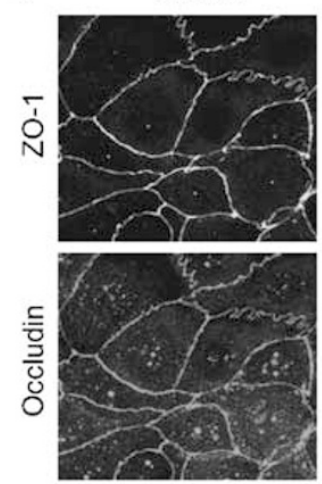

$\mathrm{H}_{2} \mathrm{O}_{2}+\mathrm{ML} 7$

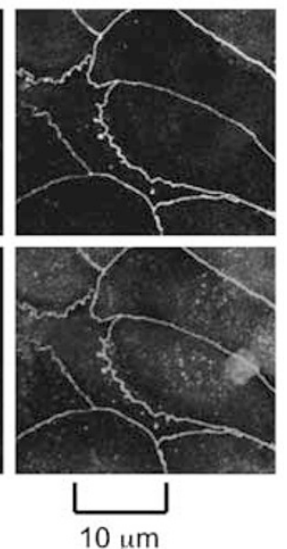

Figure 4 MLCK activity mediates hydrogen peroxide-induced tight junction disruption. NRC-1 cell monolayers were incubated with (gray) or without ML-7 (white and black bars) followed by incubation with (black and gray bars) or without (white bars) hydrogen peroxide for 120 min. Protein extracts were immunoblotted for p-MLC and $\beta$-actin (a). TER (b) and inulin flux (c) were measured. Values are shown as mean \pm s.e.m. $(n=6)$. Asterisks indicate the values that are significantly $(P<0.05)$ different from the corresponding control values. Symbol, \#, indicates the values that are significantly $(P<0.05)$ different from cells treated with hydrogen peroxide in the absence of ML-7. Cell monolayers were fixed and stained for occludin and ZO-1 (d). Fluorescence images were collected using a confocal microscope.

inhibitor significantly attenuated EGF-mediated prevention of hydrogen peroxide-induced decrease in TER (Figure 10a) and increase in inulin permeability (Figure 10b). ET-18$\mathrm{OCH}_{3}$ also prevented EGF-mediated attenuation of hydrogen peroxide-induced redistribution of occludin and ZO-1 from the intercellular junctions (Figure 10c). Similarly, Ro-320432, a PKC-selective inhibitor, prevented EGF-mediated attenuation of hydrogen peroxide-induced decrease in TER, increase in inulin permeability and redistribution of occludin and ZO-1 from the intercellular junctions. ET-18- $\mathrm{OCH}_{3}$ or Ro-32-0432 by themselves produced no significant influence on TER, inulin flux or junctional distribution of occludin and ZO-1 in control and hydrogen peroxide-treated cell monolayers.

\section{EGF Prevents Hydrogen Peroxide-Induced Barrier Dysfunction in Mz-ChA-1 Cell Monolayers}

Mz-ChA-1 cell is a human bile duct epithelial cell line that forms a polarized cholangiocyte monolayer when grown in culture. The barrier function of this cholangiocyte monolayer is weak compared with that of NRC-1 cell monolayers. However, treatment of Mz-ChA-1 cell monolayers with hydrogen peroxide significantly decreased TER (Figure 11a) and increased inulin permeability (Figure 11b). This effect of hydrogen peroxide was attenuated by pretreatment of cell monolayers with ML-7 or PP2. The hydrogen peroxideinduced effect on TER and inulin flux was attenuated by the pretreatment of cells with EGF. This effect of EGF was prevented by ET-18- $\mathrm{OCH}_{3}$ or Ro-32-0432 (Figure 11).

\section{DISCUSSION}

Although evidence indicates that oxidative stress is associated with the bile duct-associated pathology of liver, ${ }^{10,28,29}$ the mechanism of oxidative stress-induced bile duct injury is unclear. In the present study, using a primary cell line of rat bile duct epithelium and a human cholangiocarcinoma cell line, we show that oxidative stress induced by hydrogen peroxide results in compromised epithelial barrier function. The barrier function of bile duct epithelium is vital to the liver health as it prevents the diffusion of toxic bile components into liver parenchyma, thus protecting the hepatocytes and other cells from bile acid-induced injury. Disruption of barrier function and bile acid-induced hepatocyte injury has a crucial role in the pathogenesis of liver disease. 
a

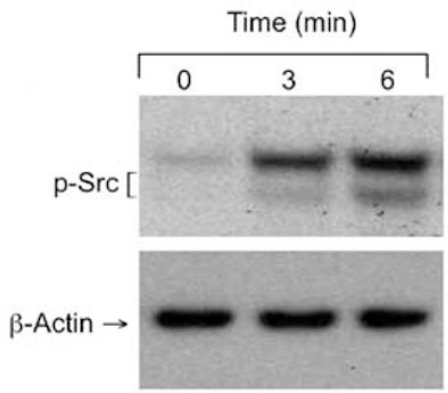

C

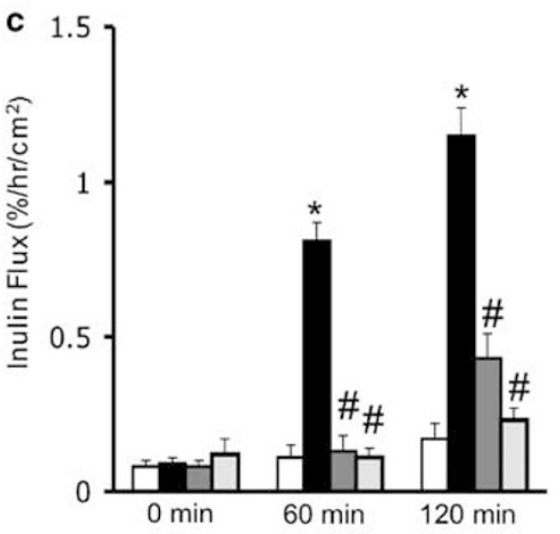

b

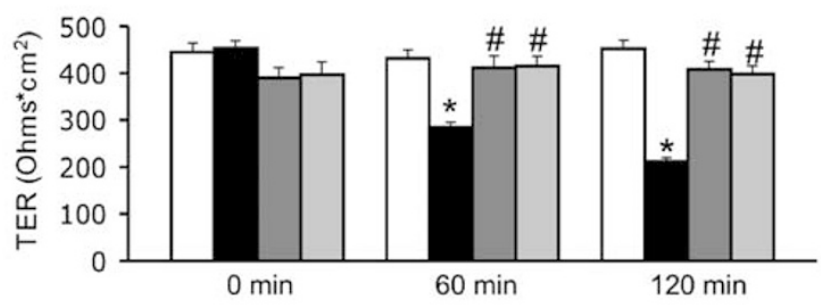

d

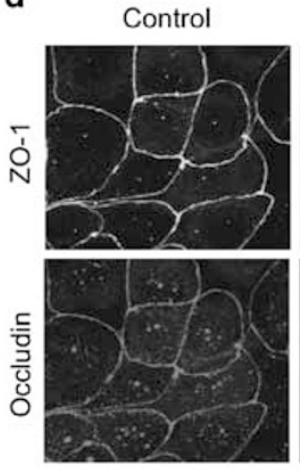

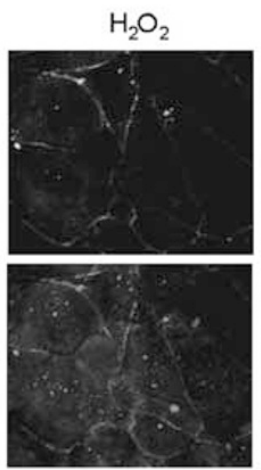

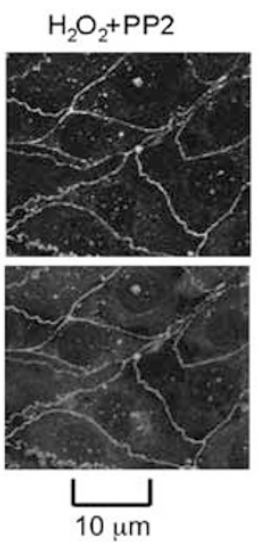

Figure 5 Src kinase activity mediates hydrogen peroxide-induced tight junction disruption. NRC-1 cell monolayers were incubated without (white and black bars) or with genistein (dark gray bars) or PP2 (light gray bars) followed by incubation with (black bars) or without (white bars) hydrogen peroxide for $120 \mathrm{~min}$. Protein extracts were immunoblotted for c-Src(pY418) and $\beta$-actin (a). TER (b) and inulin flux (c) were measured. Values are shown as mean \pm s.e.m. $(n=6)$. Asterisks indicate the values that are significantly $(P<0.05)$ different from the corresponding control values. Symbol, \#, indicates the values that are significantly $(P<0.05)$ different from values for cells treated with hydrogen peroxide in the absence of PP2. Cell monolayers were fixed and stained for occludin and ZO-1 (d). Fluorescence images were collected using a confocal microscope.

Furthermore, the factors that prevent oxidative stressinduced barrier function of bile duct epithelium is crucial to our understanding of the regulation of bile duct epithelial barrier function. The present study shows that EGF, a gastrointestinal mucosal protective factor, prevents hydrogen peroxide-induced tight junction disruption and barrier dysfunction.

Decrease in TER and increase in inulin permeability without altering cell viability show that hydrogen peroxide causes increase in paracellular permeability in the bile duct epithelium. Redistribution of tight junction proteins, occludin and ZO-1, from the intercellular junctions into the intracellular compartments indicated that hydrogen peroxide-induced barrier dysfunction was caused by the disruption of tight junctions. Occludin and ZO-1 are the most widely characterized tight junction proteins. Organization of these proteins involves an interaction of $\mathrm{ZO}-1$ with the intracellular, C-terminal domain of occludin. ${ }^{30}$ Redistribution of these proteins from the intercellular junctions into the intracellular compartment in hydrogen peroxide-treated cholangiocyte monolayer is a clear indication of disrupted tight junctions. The hydrogen peroxide concentration used in this study is similar to those $(400-1000 \mu \mathrm{M})$ used in previous experiments in other laboratories. ${ }^{31,32}$ Accurate measurement of hydrogen peroxide concentration in vivo is difficult due to

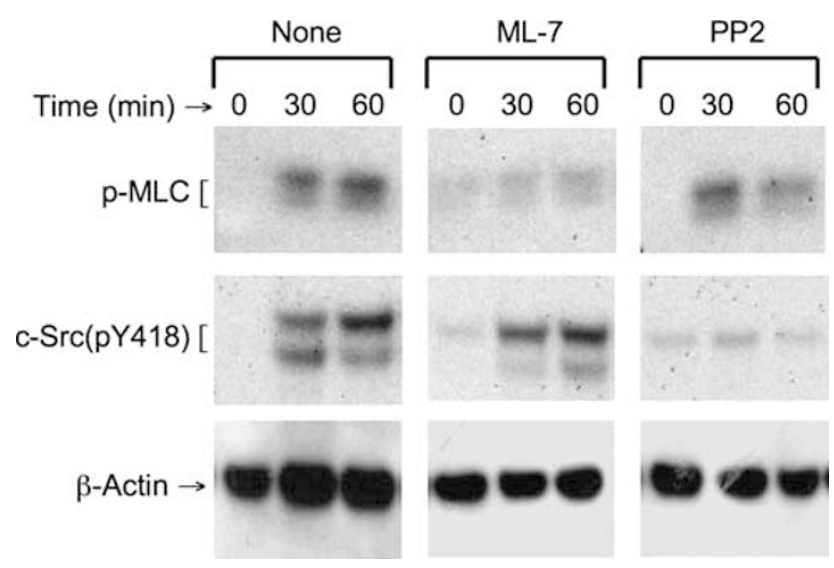

Figure 6 Hydrogen peroxide-induced activation of MLCK and c-Src are independent of each other. NRC-1 cell monolayers were incubated with or without ML-7 or PP2 for 30 min before incubation with hydrogen peroxide $(500 \mu \mathrm{M})$ for varying times. Protein extracts were immunoblotted for $\mathrm{p}-\mathrm{MLC}$, c-Src(pY418) and $\beta$-actin.

high reactivity of this molecule and spatial differences in hydrogen peroxide at subcellular levels. Evidence indicates that very high level of hydrogen peroxide is detected in neutrophil-nonphagocytosable surface contact points, which is not accessible to catalase. ${ }^{33}$ 

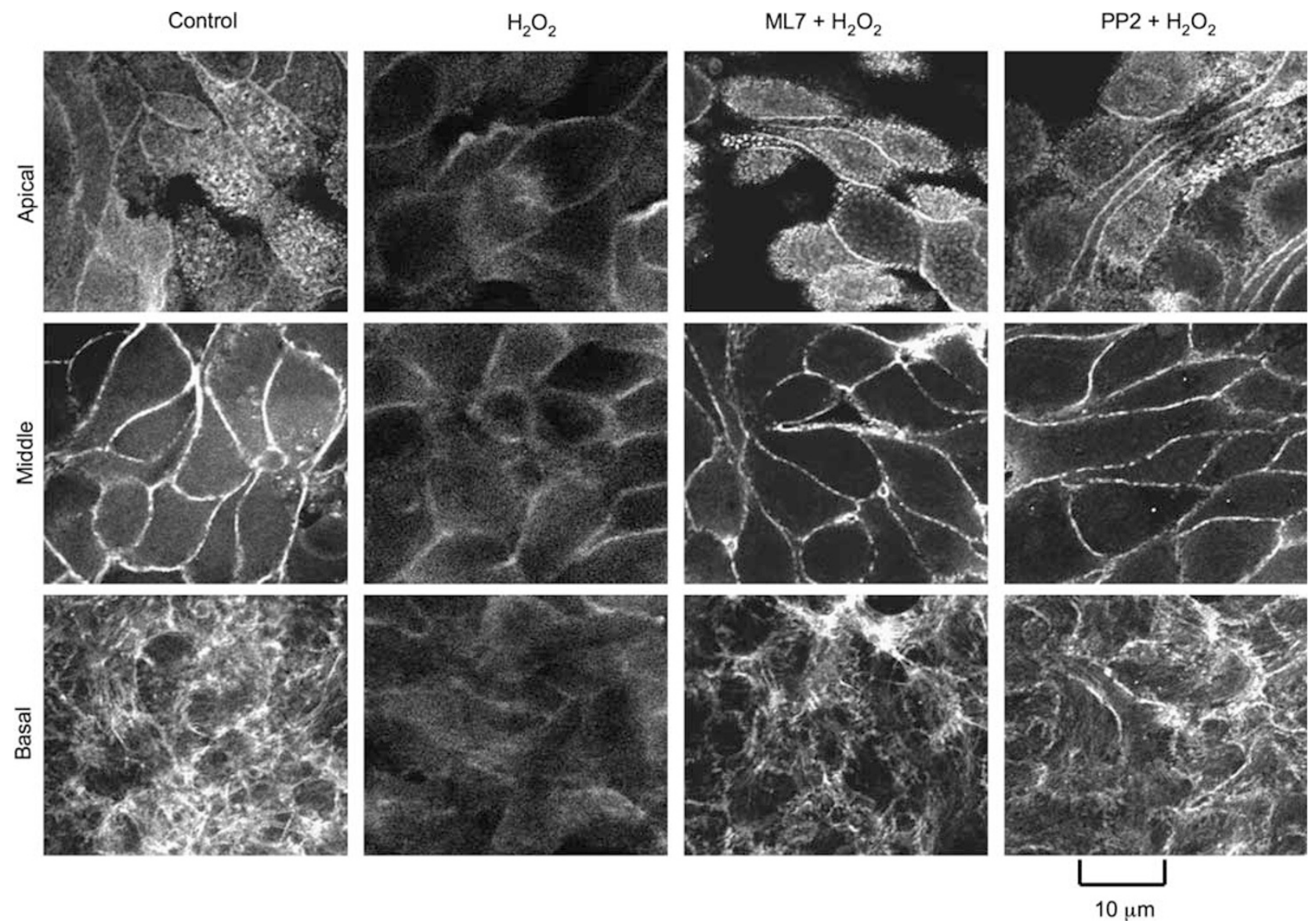

Figure 7 Hydrogen peroxide induces reorganization of actin cytoskeleton by an MLCK and Src kinase-dependent mechanism. NRC-1 cell monolayers were pretreated with or without ML-7 or PP2 for $30 \mathrm{~min}$ before incubation with hydrogen peroxide $(500 \mu \mathrm{M})$ for 90 min. F-actin in paraformaldehyde-fixed cell monolayers was stained with AlexaFlour-488-phalloidin. Fluorescence images from $1 \mu \mathrm{m}$ optical sections were collected using a confocal microscope. Images from $1 \mu \mathrm{m}$ section of apical end (Apical), mid cell (Middle) and basal end (Basal) are presented.

Co-localization of E-cadherin and $\beta$-catenin at the intercellular junctions in NRC-1 cell monolayers indicated that cholangiocytes do form adherens junctions. Very little is known about the adherens junctions in bile duct epithelium. Distribution of E-cadherin and $\beta$-catenin at the junctions of NRC-1 cell monolayers appeared diffuse unlike much more discrete organization of these proteins in other epithelial cells. ${ }^{34}$ This is consistent with the flat and wide morphologic appearance of cholangiocytes. Incubation with hydrogen peroxide induced a redistribution of both E-cadherin and $\beta$-catenin from the intercellular junctions, indicating that hydrogen peroxide also disrupts adherens junctions. Previous studies have shown that disruption of adherens junctions leads to disruption of tight junctions. ${ }^{35}$ Therefore, it is likely that adherens junction disruption has a role in facilitating tight junction disruption in bile duct epithelium.

Activation of MLCK is known to cause disruption of tight junctions and increased paracellular permeability in the intestinal and lung epithelia. ${ }^{20,36}$ MLCK activation in bile duct epithelium and its influence on tight junction permeability is unknown. A rapid increase in the levels of p-MLC indicates that hydrogen peroxide activates MLCK. Attenuation of hydrogen peroxide-induced tight junction disruption and barrier dysfunction by ML-7 indicated that MLCK is involved in hydrogen peroxide-induced tight junction disruption in NRC-1 cell monolayers. This is the first report of MLCK activation in a bile duct epithelium and its influence on the integrity of tight junctions and barrier function.

Our previous studies showed that c-Src has a crucial role in the regulation of tight junction integrity in the intestinal epithelium. ${ }^{37}$ The present study shows that Src kinase activity is also involved in hydrogen peroxide-induced tight junction disruption in NRC-1 cell monolayers. Rapid increase in the level of $\mathrm{c}-\mathrm{Src}(\mathrm{pY} 418)$ indicated that hydrogen peroxide activates $\mathrm{c}$-Src in NRC-1 cells, and attenuation of tight junction disruption and barrier dysfunction by PP2 demonstrates that Src kinase activity is involved in the mechanism of hydrogen peroxide-induced tight junction disruption and barrier dysfunction. The present study also indicates that hydrogen peroxide-induced activations of MLCK and c-Src are independent of each other. Hydrogen peroxide-induced 

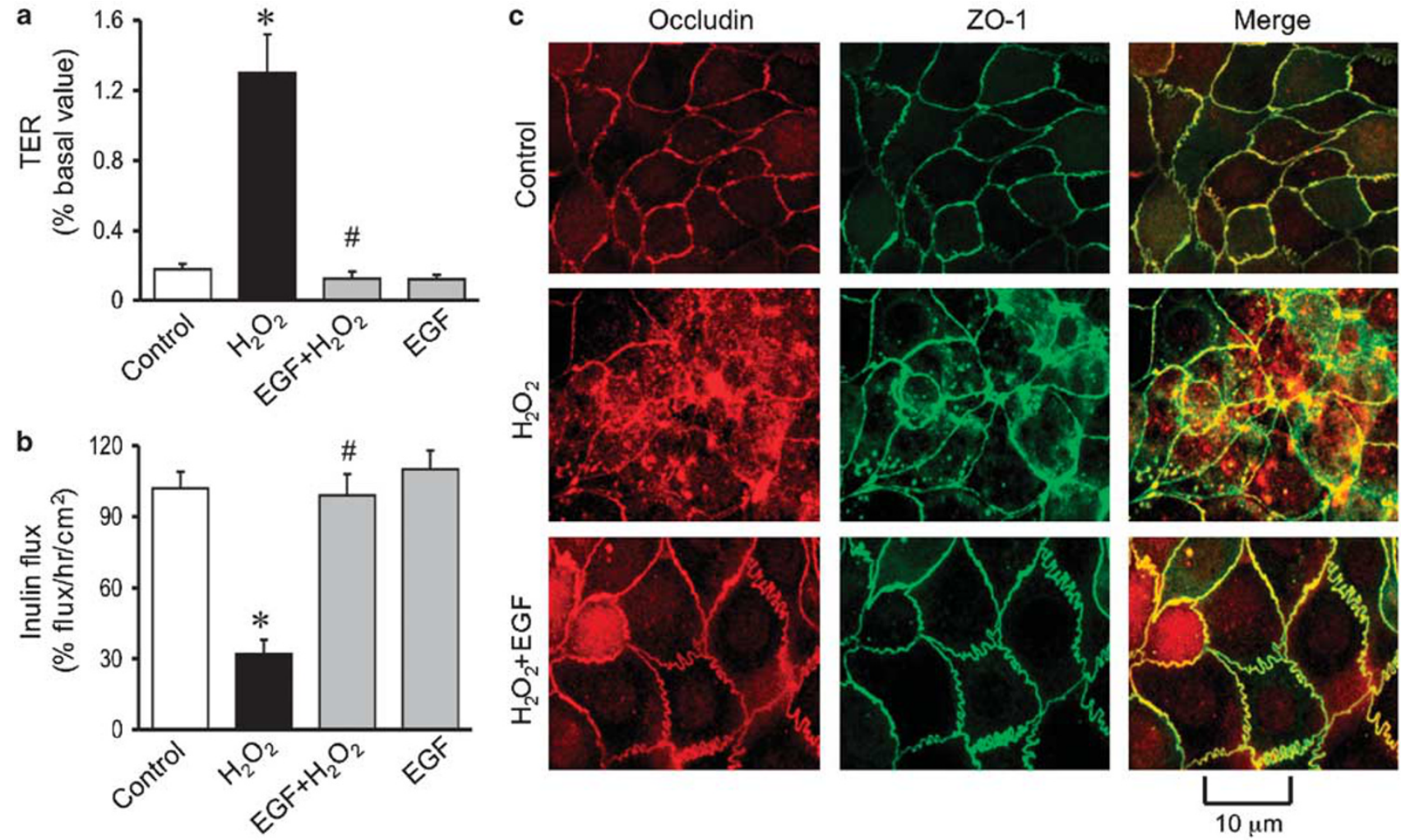

Figure 8 EGF attenuates hydrogen peroxide-induced tight junction disruption. (a, b) NRC-1 cell monolayers were incubated with or without EGF ( $30 \mathrm{nM}$ ) for $10 \mathrm{~min}$ followed by administration of hydrogen peroxide $(500 \mu \mathrm{M})$ for $30 \mathrm{~min}$. TER (a) and inulin flux (b) were measured. Values are shown as mean \pm s.e.m. $(n=6)$. Asterisks indicate the values that are significantly $(P<0.05)$ different from the corresponding control values. Symbol, \#, indicates the values that are significantly $(P<0.05)$ different from values for cells treated with hydrogen peroxide in the absence of EGF. (c) Cell monolayers were fixed and stained for occludin and ZO-1. Fluorescence images were collected using a confocal microscope.

a

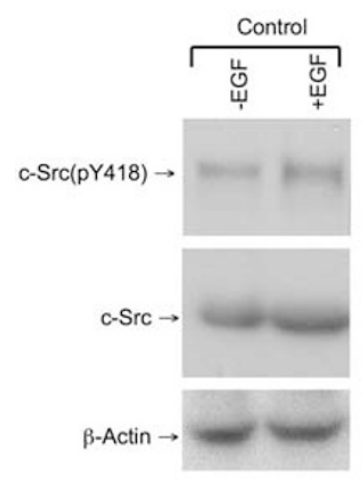

b
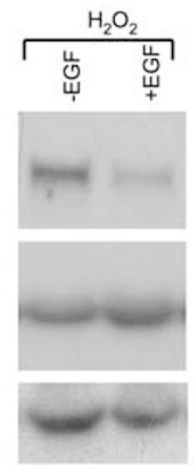
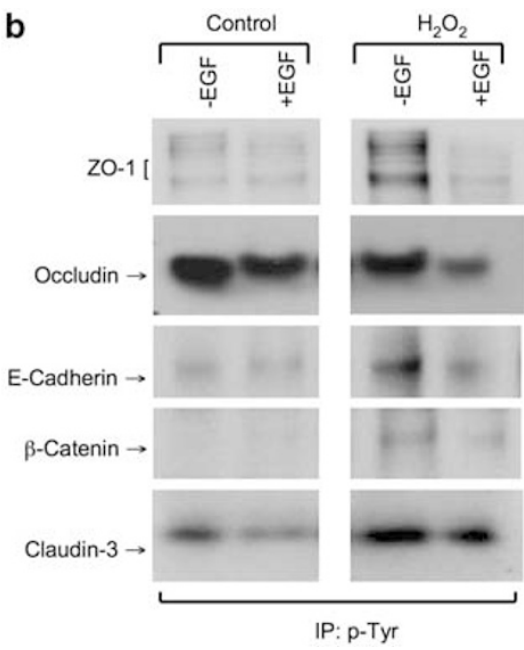

Figure 9 EGF attenuates hydrogen peroxide-induced Tyr-phosphorylation of tight junction and adherens junction proteins. (a) NRC-1 cell monolayers were incubated with or without EGF $(30 \mathrm{nM})$ for $10 \mathrm{~min}$ followed by administration of hydrogen peroxide $(500 \mu \mathrm{M})$ for $30 \mathrm{~min}$. Protein extracts were immunoblotted for c-Src(pY418) and c-Src. (b) Cell monolayers pretreated with or without EGF were incubated with or without hydrogen peroxide $(500 \mu \mathrm{M})$ for $90 \mathrm{~min}$. Phospho-tyrosine from the denatured protein extracts was immunoprecipitated and immunoblotted for tight junction and adherens junction proteins.

increase in p-MLC was attenuated by ML-7, but unaffected by PP2. On the other hand, hydrogen peroxide-induced increase in $\mathrm{c}-\mathrm{Src}(\mathrm{pY} 418)$ was attenuated by PP2, but not by ML-7. Therefore, hydrogen peroxide activates multiple signaling pathways with multiple targets that in concert may affect the integrity of tight junctions. 


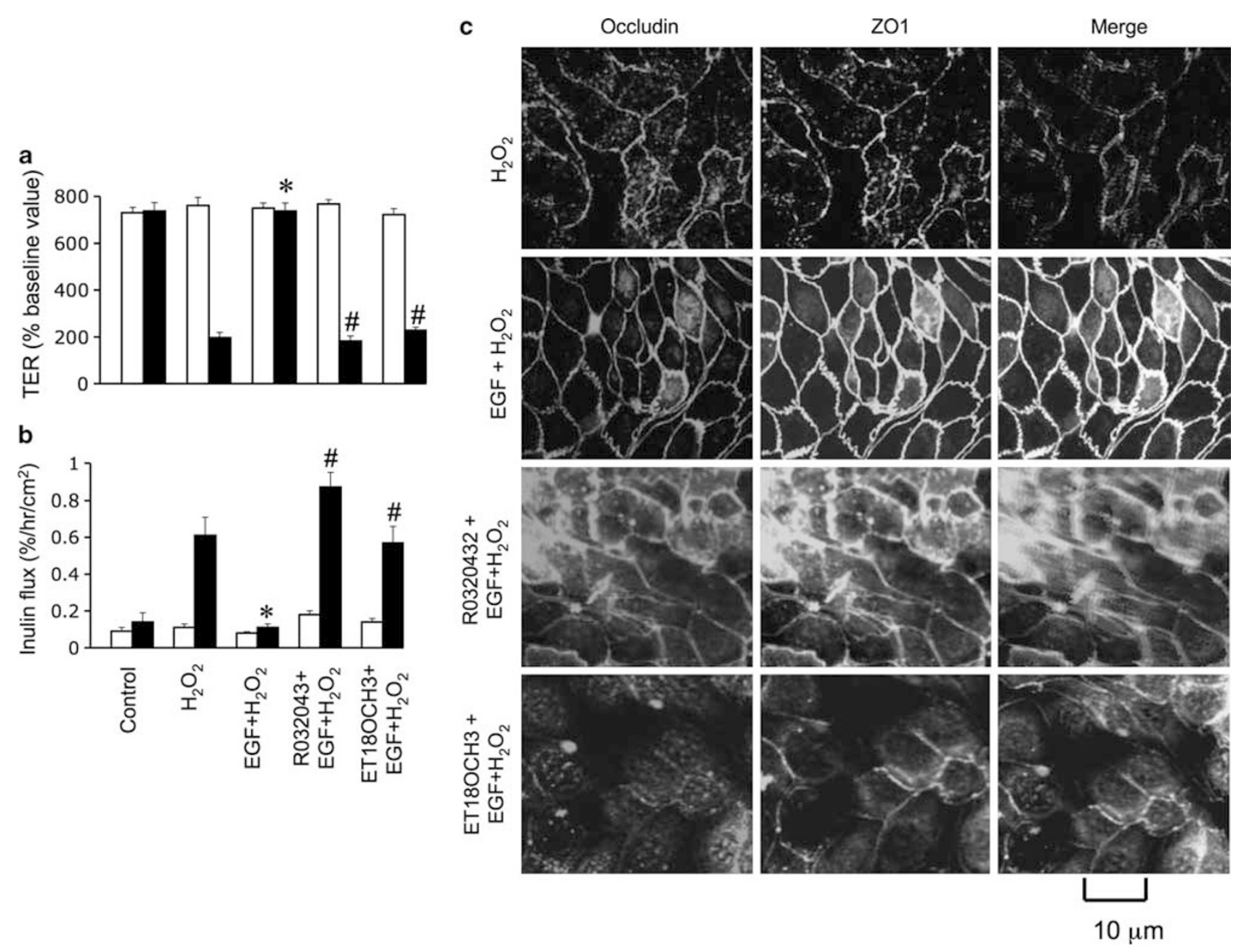

Figure 10 PLC $\gamma$ and PKC activities mediate EGF-mediated protection of tight junction from hydrogen peroxide. (a, b) NRC-1 cell monolayers were incubated with or without ET-18-OCH $(15 \mu \mathrm{M})$ or Ro-32-0432 $(1 \mu \mathrm{M})$ for 60 min followed by incubation with or without hydrogen peroxide for 120 min. TER (a) and inulin flux (b) were measured before (white bars) and after (black bars) hydrogen peroxide treatment. Values are shown as mean \pm s.e.m. ( $n=6)$. Asterisks indicate the values that are significantly $(P<0.05)$ different from the corresponding values for hydrogen peroxide group. Symbol, \#, indicates the values that

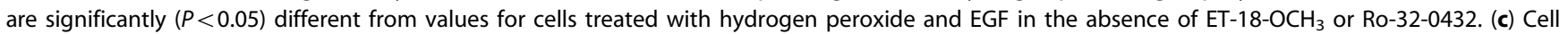
monolayers were fixed and stained for occludin and ZO-1. Fluorescence images were collected using a confocal microscope.

Although actin cytoskeleton seems to have an important role in the regulation of cholangiocyte functions, ${ }^{38,39}$ very little is known about the organization of actin cytoskeleton in bile duct epithelium. The present study shows that actin cytoskeleton in NRC-1 cell monolayers is organized into apical microvillar bundles, middle cortical network and basal network of stress fibers. Interestingly, hydrogen peroxide treatment resulted in a dramatic loss of actin organizations at all three levels. Attenuation of hydrogen peroxide-induced actin reorganization by ML-7 and PP2 indicated the roles of both MLCK and Src kinase activities in disruption of actin cytoskeleton. It is not clear how these activities are involved in the disruption of actin cytoskeleton. Modulation of actomyosin ring structure and tyrosine phosphorylation of actinbinding proteins are likely mechanisms.

It is well established that EGF protects the gastrointestinal mucosa from a variety of insults. ${ }^{24}$ EGF was shown to have a role in liver regeneration and hepatocellular carcinoma as a potent mitogen. ${ }^{40-42}$ EGF effect in bile duct epithelium, however, is unknown. The present study, for the first time, demonstrates that EGF has a protective role in normal cholangiocytes. EGF attenuated hydrogen peroxide-induced disruption of tight junctions and barrier dysfunction. EGF is predominantly produced in salivary glands and kidney and is released into the gastrointestinal lumen and renal tubules. A significant body of evidence indicates that EGF is also released into circulation, and liver is the principal organ that clears the plasma EGF including its biliary secretion EGF. ${ }^{43}$ Therefore, EGF receptor activation in the bile duct epithelium is likely to influence the bile duct function under physiologic and pathophysiologic conditions.

The present study shows that one of the mechanisms by which EGF protects tight junctions in NRC-1 cell monolayers involves suppression of hydrogen peroxide-induced c-Src 
a
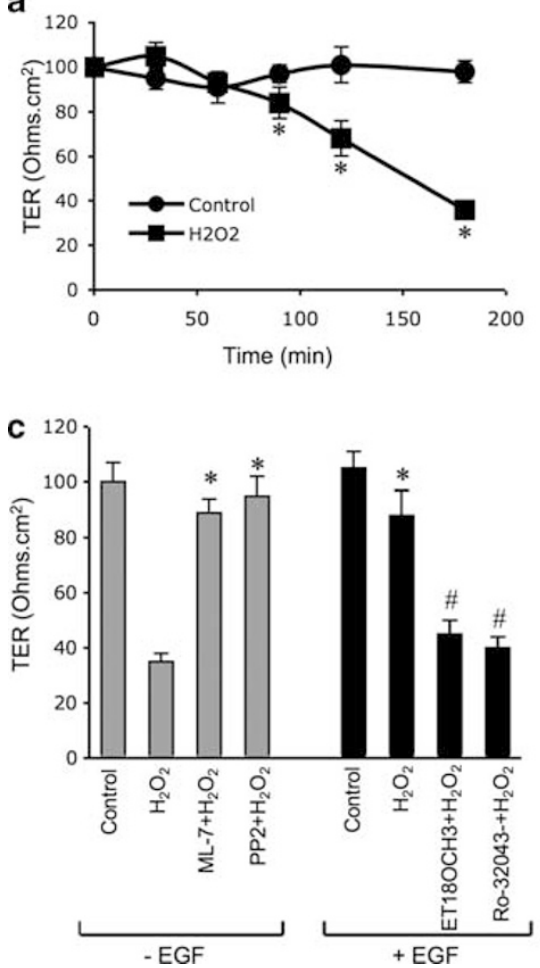

b
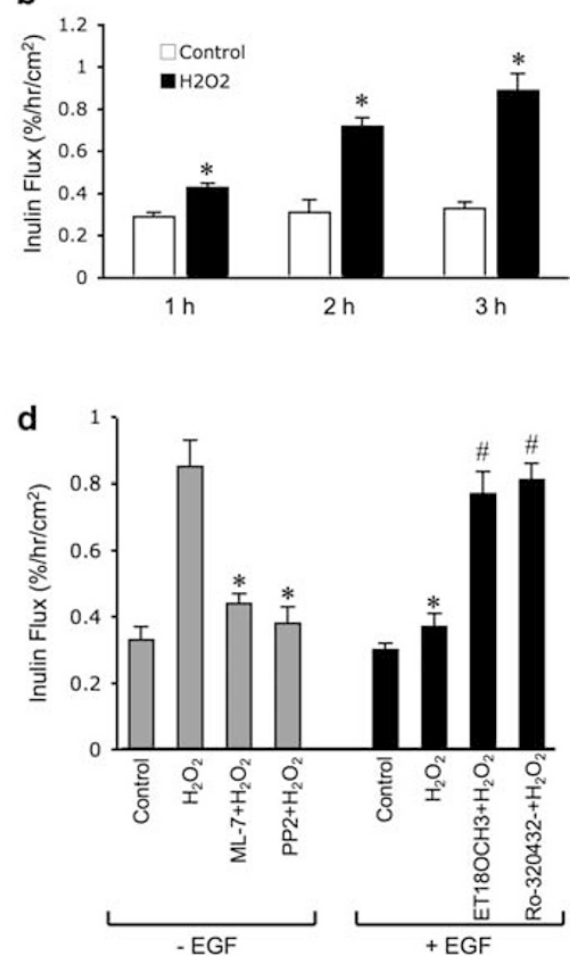

Figure 11 Hydrogen peroxide disrupts barrier function and EGF prevents this effect in Mz-ChA-1 cell monolayers. (a, b) Mz-ChA-1 cell monolayers were incubated with $(\mathbf{a})$ or without $(\bigcirc) 200 \mu \mathrm{M}$ hydrogen peroxide for varying times. TER $(\mathbf{a})$ and inulin permeability (b) were measured at varying times. Values are shown as mean \pm s.e.m. $(n=6)$. Asterisks indicate the values that are significantly $(P<0.05)$ different from the corresponding control values. $(\mathbf{c}$, d) Cell monolayers were pretreated with different inhibitors either $60 \mathrm{~min}$ before hydrogen peroxide (ML-7 and PP2) or 50 min before EGF administration (ET-18$\mathrm{OCH} 3$ and Ro-32-0432). EGF was administered $10 \mathrm{~min}$ before hydrogen peroxide. TER (c) and inulin permeability (d) were measured at $2 \mathrm{~h}$ after hydrogen peroxide. Values are shown as mean \pm s.e.m. $(n=6)$. Asterisks indicate the values that are significantly $(P<0.05)$ different from the corresponding values for hydrogen peroxide group. The symbol \# indicates the values that are significantly $(P<0.05)$ different from the corresponding values for hydrogen peroxide + EGF group.

activation. Our previous studies showed that c-Src-induced Tyr-phosphorylation of occludin on specific tyrosine residues results in loss of its interaction with ZO-1 and weakening of tight junction integrity. ${ }^{25}$ Similarly, c-Src-induced Tyr-phosphorylation of $\beta$-catenin result in loss of adherens junction integrity. ${ }^{26}$ The potential role of Src kinase activity in hydrogen peroxide-induced tight junction disruption raised the question whether $\mathrm{H}_{2} \mathrm{O}_{2}$ increased tyrosine phosphorylation of tight junction and adherens junction proteins in NRC-1 cell monolayers. Results indicate that hydrogen peroxide treatment increased the levels of tyrosine phosphorylated E-cadherin and $\beta$-catenin, suggesting a potential loss of interaction between E-cadherin and $\beta$-catenin in hydrogen peroxide-treated cell monolayers.

Occludin was found to be highly tyrosine phosphorylated in both untreated and hydrogen peroxide-treated cell monolayers. But, Tyr-phosphorylation of ZO-1 and claudin-3 was increased by hydrogen peroxide. Although ZO-1 was previously shown to undergo tyrosine phosphorylation during the tight junction disruption in Caco-2 cell monolayers, the function of ZO-1 phosphorylation in the mechanism of tight junction disruption is unclear. EGF treatment reduced the levels of tyrosine phosphorylated E-cadherin, $\beta$-catenin, ZO-1 and claudin-3, which is likely one of the mechanisms associated with EGF-mediated protection of tight junctions from hydrogen peroxide in NRC-1 cell monolayers. Although high levels of tyrosine phosphorylated occludin were equally high in both untreated and hydrogen peroxide-treated cell monolayers, EGF treatment caused a reduction of occludin phosphorylation in both untreated and hydrogen peroxidetreated cell monolayers. In general, tyrosine phosphorylation of tight junction and adherens junction proteins is high in hydrogen peroxide-treated cell monolayers, while EGF attenuates such protein tyrosine phosphorylation.

The mechanism of EGF-mediated protection of epithelial integrity is known to involve activation of several intracellular signaling pathways. One such mechanism is activation of PLC $\gamma$ and PLC $\gamma$-mediated activation of PKC. Our recent study showed that EGF rapidly activates PLC $\gamma$ and PKC in Caco-2 cell monolayers. ${ }^{27}$ Attenuation of EGFmediated protection of tight junctions from hydrogen peroxide by ET-18- $\mathrm{OCH}_{3}$ and Ro-32-0432 indicated that PLC $\gamma$ and PKC activities are involved in EGF-mediated protection of tight junctions in NRC-1 cell monolayers. 
We further examined the effect of hydrogen peroxide and EGF on barrier function in Mz-ChA-1 cell monolayers. MzChA-1 cell is a human cholangiocarcinoma cell line that grows in culture to form a differentiated monolayer of cholangiocytes. Although this cell monolayer is relatively leaky compared with NRC-1 cell monolayers, hydrogen peroxide treatment significantly disrupted the barrier function (decrease in TER and increase in inulin permeability). MLCK and Src kinase inhibitors attenuated this effect of hydrogen peroxide. EGF prevented hydrogen peroxide-induced barrier dysfunction, which was attenuated by PLC $\gamma$ and PKC inhibitors. These results demonstrate that the phenomenon of hydrogen peroxide and EGF effects on barrier function is likely to exist in all types of bile duct epithelia, and not confined to a single cell line.

In conclusion, oxidative stress induced by hydrogen peroxide disrupts tight junctions and adherens junctions, and induces barrier dysfunction in bile duct epithelium by an MLCK and Src kinase-dependent mechanism. Furthermore, EGF ameliorates hydrogen peroxide-induced tight junction disruption in bile duct epithelium by a PLC $\gamma$ and PKC-dependent mechanism.

\section{ACKNOWLEDGEMENT}

This study was supported mainly by a grant from Mussette and Allen Morgan Foundation for Primary Sclerosing Cholangitis and partially by National Institute of Health Grants R01-DK55532 and R01-AA12307.

\section{DISCLOSURE/CONFLICT OF INTEREST}

The authors declare no conflict of interest.

1. Luedde T, Heinrichsdorff J, de Lorenzi R, et al. IKK1 and IKK2 cooperate to maintain bile duct integrity in the liver. Proc Natl Acad Sci USA 2008;105:9733-9738.

2. Hadj-Rabia S, Baala L, Vabres $P$, et al. Claudin-1 gene mutations in neonatal sclerosing cholangitis associated with ichthyosis: a tight junction disease. Gastroenterology 2004;127:1386-1390.

3. Hanada S, Harada $M$, Koga $H$, et al. Tumor necrosis factor-alpha and interferon-gamma directly impair epithelial barrier function in cultured mouse cholangiocytes. Liver Int 2003;23:3-11.

4. Nagtzaam IF, van Geel M, Driessen A, et al. Bile duct paucity is part of the neonatal ichthyosis-sclerosing cholangitis phenotype. $\mathrm{Br} J$ Dermatol 2010;163:205-207.

5. Sheth $P$, Delos Santos N, Seth A, et al. Lipopolysaccharide disrupts tight junctions in cholangiocyte monolayers by a c-Src-, TLR4-, and LBPdependent mechanism. Am J Physiol Gastrointest Liver Physiol 2007;293:G308-G318.

6. Fickert $P$, Fuchsbichler $A$, Wagner $M$, et al. Regurgitation of bile acids from leaky bile ducts causes sclerosing cholangitis in Mdr2 (Abcb4) knockout mice. Gastroenterology 2004;127:261-274.

7. Rao R. Oxidative stress-induced disruption of epithelial and endothelial tight junctions. Front Biosci 2008;13:7210-7226.

8. Rao R. Occludin phosphorylation in regulation of epithelial tight junctions. Ann N Y Acad Sci 2009;1165:62-68.

9. Joly $\mathrm{P}$, Gilbert $\mathrm{D}$, Thomine $\mathrm{E}$, et al. Immunofluorescence and immunoelectron microscopy analyses of a human monoclonal antiepithelial cell surface antibody that recognizes a $185-\mathrm{kD}$ polypeptide: a component of the paraneoplastic pemphigus antigen complex? J Invest Dermatol 1993;101:339-345.

10. Cecere A, Tancredi L, Gattoni A. Primary sclerosing cholangitis. Panminerva Med 2002;44:313-323.

11. Shackel NA, McGuinness PH, Abbott CA, et al. Identification of novel molecules and pathogenic pathways in primary biliary cirrhosis: CDNA array analysis of intrahepatic differential gene expression. Gut 2001;49:565-576.

12. Salem TA, El-Refaei MF, Badra GA. Study of antioxidant enzymes level and phagocytic activity in chronic liver disease patients. Egypt J Immunol 2003;10:37-45.

13. Miranda-Diaz AG, Hermosillo-Sandoval JM, Ortiz GG, et al. Serum oxidative stress is increased in patients with post cholecystectomy bile duct injury. Rev Esp Enferm Dig 2010;102:352-356.

14. Lissidini G, Piccinni G, Portincasa $P$, et al. Surgically-induced bile duct injury is followed by early hepatic oxidative stress. A preliminary experimental study in rats. Hepatogastroenterology 2009;56: 602-605.

15. Tiao MM, Lin TK, Wang PW, et al. The role of mitochondria in cholestatic liver injury. Chang Gung Med J 2009;32:346-353.

16. Portincasa $P$, Grattagliano I, Testini $M$, et al. Parallel intestinal and liver injury during early cholestasis in the rat: modulation by bile salts and antioxidants. Free Radic Biol Med 2007;42:1381-1391.

17. Zhong Z, Froh M, Wheeler MD, et al. Viral gene delivery of superoxide dismutase attenuates experimental cholestasis-induced liver fibrosis in the rat. Gene Ther 2002;9:183-191.

18. Jaiswal M, LaRusso NF, Shapiro RA, et al. Nitric oxide-mediated inhibition of DNA repair potentiates oxidative DNA damage in cholangiocytes. Gastroenterology 2001;120:190-199.

19. Clayburgh DR, Barrett TA, Tang $Y$, et al. Epithelial myosin light chain kinase-dependent barrier dysfunction mediates $T$ cell activationinduced diarrhea in vivo. J Clin Invest 2005;115:2702-2715.

20. Dull RO, Dinavahi R, Schwartz L, et al. Lung endothelial heparan sulfates mediate cationic peptide-induced barrier dysfunction: a new role for the glycocalyx. Am J Physiol Lung Cell Mol Physiol 2003;285:L986-L995.

21. Madara JL, Stafford J, Barenberg D, et al. Functional coupling of tight junctions and microfilaments in T84 monolayers. Am J Physiol 1988;254(3 Part 1):G416-G423.

22. Meza I, Ibarra G, Sabanero M, et al. Occluding junctions and cytoskeletal components in a cultured transporting epithelium. J Cell Biol 1980;87(3 Part 1):746-754.

23. Stevenson BR, Begg DA. Concentration-dependent effects of cytochalasin $D$ on tight junctions and actin filaments in MDCK epithelial cells. J Cell Sci 1994;107(Part 3):367-375.

24. Rao RK. Biologically active peptides in the gastrointestinal lumen. Life Sci 1991;48:1685-1704.

25. Elias BC, Suzuki T, Seth A, et al. Phosphorylation of Tyr-398 and Tyr-402 in occludin prevents its interaction with ZO-1 and destabilizes its assembly at the tight junctions. J Biol Chem 2009;284:1559-1569.

26. Sheth $\mathrm{P}$, Seth $\mathrm{A}$, Atkinson $\mathrm{KJ}$, et al. Acetaldehyde dissociates the PTP1B-E-cadherin-beta-catenin complex in Caco-2 cell monolayers by a phosphorylation-dependent mechanism. Biochem J 2007;402: 291-300.

27. Suzuki T, Seth A, Rao R. Role of phospholipase Cgamma-induced activation of protein kinase Cepsilon (PKCepsilon) and PKCbetal in epidermal growth factor-mediated protection of tight junctions from acetaldehyde in Caco-2 cell monolayers. J Biol Chem 2008;283: 3574-3583.

28. Assimakopoulos SF, Grintzalis K, Thomopoulos KC, et al. Plasma superoxide radical in jaundiced patients and role of xanthine oxidase. Am J Med Sci 2008;336:230-236.

29. Harada K, Nakanuma Y. Molecular mechanisms of cholangiopathy in primary biliary cirrhosis. Med Mol Morphol 2006;39:55-61.

30. Furuse $\mathrm{M}$, Itoh $\mathrm{M}$, Hirase $\mathrm{T}$, et al. Direct association of occludin with ZO1 and its possible involvement in the localization of occludin at tight junctions. J Cell Biol 1994;127(6 Part 1):1617-1626.

31. Sabaretnam T, Harris MJ, Kockx M, et al. Effects of hydrogen peroxide and apolipoprotein $E$ isoforms on apolipoprotein $E$ trafficking in HepG2 cells. Clin Exp Pharmacol Physiol 2009;36:e96-e102.

32. Sato $H$, Takeo $T$, Liu $Q$, et al. Hydrogen peroxide mobilizes $\mathrm{Ca} 2+$ through two distinct mechanisms in rat hepatocytes. Acta Pharmacol Sin 2009;30:78-89.

33. Vissers MC, Day WA, Winterbourn CC. Neutrophils adherent to a nonphagocytosable surface (glomerular basement membrane) produce oxidants only at the site of attachment. Blood 1985;66: $161-166$.

34. Rao RK, Basuroy S, Rao VU, et al. Tyrosine phosphorylation and dissociation of occludin-ZO-1 and E-cadherin-beta-catenin complexes 
from the cytoskeleton by oxidative stress. Biochem J 2002;368 (Part 2):471-481.

35. Seth $A$, Sheth $P$, Elias $B C$, et al. Protein phosphatases $2 A$ and 1 interact with occludin and negatively regulate the assembly of tight junctions in the CACO-2 cell monolayer. J Biol Chem 2007;282: 11487-11498.

36. Clayburgh DR, Rosen S, Witkowski ED, et al. A differentiationdependent splice variant of myosin light chain kinase, MLCK1, regulates epithelial tight junction permeability. J Biol Chem 2004;279:55506-55513.

37. Basuroy $S$, Sheth $P$, Kuppuswamy $D$, et al. Expression of kinase-inactive c-Src delays oxidative stress-induced disassembly and accelerates calcium-mediated reassembly of tight junctions in the Caco- 2 cell monolayer. J Biol Chem 2003;278:11916-11924.
38. Doctor RB, Dahl R, Fouassier $\mathrm{L}$, et al. Cholangiocytes exhibit dynamic, actin-dependent apical membrane turnover. Am J Physiol Cell Physiol 2002;282:C1042-C1052.

39. Doctor RB, Fouassier L. Emerging roles of the actin cytoskeleton in cholangiocyte function and disease. Semin Liver Dis 2002;22:263-276.

40. Berasain C, Castillo J, Perugorria MJ, et al. Inflammation and liver cancer: new molecular links. Ann N Y Acad Sci 2009;1155:206-221.

41. Furuse J. Growth factors as therapeutic targets in HCC. Crit Rev Oncol Hematol 2008;67:8-15.

42. Michalopoulos GK. Liver regeneration: molecular mechanisms of growth control. FASEB J 1990;4:176-187.

43. Marti U, Burwen SJ, Jones AL. Biological effects of epidermal growth factor, with emphasis on the gastrointestinal tract and liver: an update. Hepatology 1989;9:126-138. 